\title{
Vida y Crítica. Un diálogo con Julio Ramos*
}

\section{Life and Critique. A Dialogue with Julio Ramos}

Eleonora Cróquer Pedrón ${ }^{\text {a }}$

DOI: https://doi.org/10.11144/Javeriana.cl25.vcdj

Universidad Simón Bolivar, Venezuela

ecroquer@usb.ve

ORCID: https://orcid.org/0000-0002-0811-6126

Recibido: 13 Agosto 2020

Aceptado: 21 Noviembre 2020

Publicado: 20 Agosto 2021

Hay momentos singulares en que las entrevistas contienen una finalidad en si: el nudo de un concepto y su relación con un relato. Ese es el tipo de entrevista que más me interesa.

Julio Ramos

"Vida y Crítica" constituye la versión reducida de "un diálogo con Julio Ramos" que, en cierta medida, recupera y continúa el que Julio y yo no hemos dejado de sostener entre las tantas experiencias, preguntas, lecturas, elaboraciones, crisis, angustias y alegrías compartidas, desde que nos conocimos en Caracas durante el Simposio sobre Literatura y Cultura Latinoamericanas del siglo XIX organizado por la Maestría en Literatura de la Universidad Simón Bolívar en homenaje a Ángel Rama, hace ya tres décadas. Es la versión reducida, también, de un texto tramado en el intercambio epistolar de una escritura por otra que se produjo entre los primeros días de marzo y la tercera semana de abril de este 2020 devastador. Fue una suerte de respuesta inesperada a la idea de retomar cierta "entrevista" diferida por casi dos años, con la intención de que fuera incorporada en el volumen Estética y justicia. Homenaje a Julio Ramos coordinado por Hugo Herrera en conmemoración a la primera edición de Desencuentros de la Modernidad en América Latina. Literatura y politica en el siglo XIX (1989), para la Colección Dársena del Departamento de Literatura de la Pontificia Universidad Católica de Valparaíso, donde aparecerá en extenso.

En aquel momento, Julio trabajaba en la reedición de su libro imprescindible Amor y anarquía. Los escritos de Luisa Capetillo (1992), de cara a la cual había reunido una serie de lecturas críticas sobre el discurso y la figura de la emblemática anarcofeminista puertorriqueña. Mientras tanto, yo desarrollaba un ensayo sobre la inquietud que singulariza las heterónomas intervenciones orales, escritas y audiovisuales de Ramos en el campo cada vez más difuso de los estudios literarios y culturales sobre América Latina, y la potencia de un pensamiento inquietado por las paradojas del presente en el cual se inscribe, capaz de inquietar al otro al que siempre se dirige con interrogantes y anotaciones tan inesperadas como urgentes. Por supuesto, la serie de preguntas y señalamientos que había concebido dos años antes como una "entrevista" adquirieron un nuevo sentido en este momento radicalmente distinto. Pero, además, en otro tipo de texto: una entrevista que se desplaza de mi pregunta por el autor ficcionalizado - Julio X Ramos- en Por si nos da el tiempo (2002), a la pregunta de Julio por su prima discapacitada que quiere volver a casa en medio de la pandemia; y que, al hacerlo, no solo consigue mostrar "el nudo de un concepto y su relación con un relato", sino la potencia de un pensamiento donde la crítica deviene en creadora.

Eleonora Cróquer Pedrón: Quisiera comenzar esta conversación con una referencia a ese texto de alguna manera "marginal" respecto de tu trabajo crítico: Por si nos da el tiempo (2002), que se desarrolla en torno a una entrevista fabulada entre el autor - Julio X Ramos - y cierto entrevistador incómodo — Santiago Lavoe —, entre los cuales se establece una tensión casi antagónica. ¿Cómo piensas el espacio de la entrevista, tú, que

Notas de autor

\footnotetext{
${ }^{a}$ Autora de correspondencia. Correo electrónico: ecroquer@usb.ve
} 
has recurrido a ella como soporte documental de una investigación que, de la revisión del archivo, se abre al campo?

Julio Ramos: Gracias, Eleonora, por las preguntas y por tu lectura de un margen que persiste. En cierto sentido, ese margen es un excedente del trabajo crítico, aunque es posible que su filo arrastre una energía que precede o que de algún modo informa los contenidos conceptuales de la crítica. Tu pregunta supone una estrategia diacrítica que me interesa mucho como modo de leer, de organizar los materiales a partir de los límites de un objeto o zona de trabajo. Aunque ha circulado relativamente poco, Por si nos da el tiempo es uno de los textos que escribí con mayor urgencia. El texto, una mezcla de ensayo y ficción - que algunxs han identificado como una novela corta - se publicó en Beatriz Viterbo Editora, en la colección El Escribiente, una decisión que respondía al problema de la clasificación de este pequeño objeto que a su modo ponía en juego las fronteras del género literario y la noción misma de la firma del autor, Julio X Ramos. La X, por cierto, posiblemente tenía algo que ver con el quiasmo de eXcultura, el nombre de la editorial que publicó mi segundo libro, Paradojas de la letra (1996), dirigida por un avatar de Eleonora Cróquer Pedrón y María Julia Daroqui en Caracas. Fíjate cómo gira ahora tu pregunta, lo que de pronto encamina la entrevista en una zona virtual, no necesariamente ficticia, ciertamente dialógica, que me interesa mucho.

De hecho, como señalas, Por si nos da el tiempo incluye una especie de entrevista ficcionalizada, donde el entrevistador, Santiago Lavoe (un joven investigador literario, ahora metido a filósofo derridiano), me interrogaba sobre Desencuentros de la modernidad en América Latina: literatura y politica en el siglo XIX, el libro de corte más histórico que había publicado en 1989. La entrevista de Santiago Lavoe es el disparador de otra historia, la de Pepón Arroyo, un primo de mi madre que había pasado cerca de 20 años entre Esmeraldas, la provincia afrodescendiente, cimarrona, del Ecuador, y Quito, donde vino a fundar un hospedaje en el centro antiguo que llamó Hotel Puerto Rico, lugar de vida clandestina o de mala vida, vaya uno a saber.

En el contexto de ese relato, la entrevista era el recurso ideal para mezclar tiempos y enunciados distintos; contenidos, digamos, conceptuales trenzados en la historia algo ficcional de Pepón Arroyo. La entrevista es una forma ligada a la práctica de la escucha. Además, claro, es una fuente de información sobre un sujeto o un evento. Como sugieres en tu pregunta o comentario, las entrevistas también han sido clave en otras zonas de mi trabajo de investigación. Algunas fueron un dolor de cabeza, como cuando la grabadora se quedó completamente sorda durante una entrevista que le hacía a Ticio Escobar en Asunción, mientras Ticio todavía era ministro de cultura del Paraguay (2012). Todo un fracaso periodístico. O luego, a la hora de la transcripción y la edición de las entrevistas, las revisiones del léxico guaraní con que también Bartomeu Meliá, como Ticio, puntualizaba su discurso (2012). Por suerte, tuve bastante ayuda de ambos interlocutores, muy atentos a los detalles y deslices lingüísticos de la entrevista misma.

Como forma de conversación o de intercambio epistolar, la entrevista colinda con el ensayo, aunque también tiene mucho potencial narrativo. Digamos que la entrevista explicita algunas condiciones dialógicas y narrativas del ensayo y de otras formas. Te diría, incluso, que la entrevista da margen a la improvisación, lo que posibilita la expresión de ideas que apenas se están gestando, conceptos inacabados que aún no están "bien formados"; es decir que todavía no han sido sometidos a protocolos disciplinarios, o que, por alguna razón, quedan fuera del marco de una "obra". Por eso mismo, esta forma menor (en un sentido deleuziano) del trabajo de investigación a veces toca aspectos liminares o tal vez inconscientes del pensamiento crítico. En otras ocasiones, la entrevista abre el espacio de la letra a experiencias silenciadas, como ocurre con el testimonio que narra Gretel Alfonso sobre el cineasta experimental afrocubano N. Guillén Landrián —su historia de encarcelamientos, internamientos psiquiátricos y exilio-, que fue la base del documental que hice con Raydel Araoz, Retornar a La Habana con Guillén Landrián, en 2013.

Ahora, intento adelantar una serie de entrevistas a intelectuales, escritores y artistas visuales puertorriqueños, algunxs de ellxs con una visión distinta del trabajo creativo y del activismo político ante la crisis actual, las protestas del 2019 y los desastres consecutivos que ha sufrido la isla. Con suerte, las entrevistas contribuyen a producir lo que F. Jameson llamaba un mapa cognitivo de un campo de luchas, debates o 
intervenciones. Otras veces contribuyen al trabajo de campo o de preparación. Pero hay momentos singulares en los que las entrevistas contienen una finalidad en sí: el nudo de un concepto y su relación con un relato. Ese es el tipo de entrevista que más me interesa.

Eleonora: Y ¿cómo piensas tu propia entrevista ficcionalizada, allí donde esta permite no solo la incorporación de una reflexión crítica que apuntala tu trayectoria como investigador de la literatura y la cultura en América Latina, sino la inscripción de una cierta memoria personal?

Julio: Ahora que lo dices, en Por si nos da el tiempo, la entrevista ficcionalizada permite conversar sobre Desencuentros de la modernidad con un poco de distancia, desde un lugar no universitario. Además, tal como lo sugieres, en la entrevista se cuenta otra historia que acaso el entrevistador, Santiago Lavoe, no escucha bien o no descifra: la historia de Pepón Arroyo, su depresión y enganche de las drogas. Esa historia está ligada a una memoria personal (según la llamas en tu pregunta), aunque la experiencia no aparece tematizada o convertida en el objeto de un testimonio. En ese punto, la entrevista, su relación con las formas de la interpelación y la subjetivación “dime quién eres y de dónde vienes”-, se topa con un límite casi infranqueable. Desde Thomas de Quincey en las Confesiones, y al menos hasta Burroughs en Junkie, al toxicómano se le exige que lo cuente "todo". A veces, como en el caso de De Quincey, al final de sus Confesiones, el testimonio pretende incluso contribuir a la ciencia con un relato ejemplar. Pero si algo sabe el adicto (esto lo sabe cualquiera) es que todo no se puede contar. Nunca todo. No me refiero simplemente a su lugar ante la ley (en el interrogatorio o al momento de la sentencia), sino al juego mismo del poder, no solo retórico, sino moral, que frecuentemente atrapa la experiencia límite como a una mosca en ese horizonte reconocible de los géneros confesionales, la conversión o la rehabilitación. Esto sigue siendo un reto para mí, sin duda, tal vez por mis limitaciones narrativas. Conozco pocos escritores que logran escribir con desenfado sobre los males de la voluntad, como los llama Eve K. Sedwigck. Una de ellas es la formidable cronista y narradora María Moreno en Black Out, un libro de memorias y crónicas sobre el alcohol en el mundo literario bajo la dictadura argentina; otro es Juan Carlos Quiñones en sus posteos de Facebook titulados La cárcel sin límite, en los que coloca fragmentos y apuntes elípticos sobre su internamiento en un rehab del gobierno en Puerto Rico. El desenfado es clave para el desenganche de la interpelación moral que predomina en los estilos confesionales o testimoniales de la literatura sobre la adicción, su economía de la culpa y de la deuda. La culpa-deuda es un enganche tóxico de mucha circulación en los relatos morales de la adicción.

Eleonora: En Por si nos da el tiempo, el proyecto de Santiago Lavoe supone incluir al autor de Desencuentros de la modernidad en América Latina en un "libro medio ficticio armado con entrevistas a personajes (tan reales como lo soy yo, Julio X Ramos), leales hijos de zonas, cómo decirlo, laterales de América Latina" (36; énfasis del autor), que "debía llamarse Los más raros todavía, alusión y homenaje a esa especie de libro de entrevistas avant la lettre titulado Los raros de Rubén Darío" (37). Tengo un par de preguntas al respecto: ¿cómo se cruzan esa "lateralidad" y el "plus de rareza" al que se refiere el entrevistador ficcionalizado en el texto? Y, además, ¿qué le dona un "marginal” como Julio (X) Ramos a la crítica cultural?

Julio: Ah, ¿entonces te parece que Julio X Ramos es un personaje "marginal”? Hmm. Ya en Los raros Darío operaba con una noción de la semblanza afín a una idea moderna de la literatura como régimen de vidas excepcionales. Es decir, la literatura no solo como panoplia de representaciones y prácticas simbólicas, sino como un modo de reorganizar la vida, la experiencia misma, de acuerdo con ciertos principios estéticos o poéticos. Siempre me ha resultado curioso que Darío incluyera a José Martí entre sus raros. Creo que lo incluye no tan solo porque Darío veía a Martí como un antecesor, sino porque para Martí la relación entre vida y literatura se había transformado. Eso es lo que hace de Martí un escritor moderno. Curiosamente, esta transformación pasa menos por los contenidos más obvios de la biografía política, que por una relación inédita entre Martí, su experiencia (incluso política) y su voluntad de estilo. El estilo para Martí no es ya meramente un adorno o suplemento retórico, sino el despliegue de una nueva sensibilidad, un modo de responder críticamente a otros discursos sociales, racionalizados, utilitarios, para sobrevivir entre ellos. Paradójicamente, la voluntad de estilo reintroduce, entonces, una dimensión política, pero ahora mediada por la forma y la 
autoridad literaria. Por cierto, esa mediación literaria no le resta proyección pública ni efectividad pragmática a Martí, obvio que no.

En su extremo, la noción de la excentricidad y la singularidad de los raros de Darío toca lo que tú misma has llamado, en varios trabajos, historias de casos, narrativas que inscriben los bordes o fronteras de un campo normativo. Es decir, las vidas excepcionales de la literatura permiten repensar los modos de normalización. Me refiero, por ejemplo, a tu trabajo sobre la locura del pintor venezolano Armando Reverón, en cuya "vida y obra" lees el anverso estético de una modernidad petrolera y dependiente.

Eleonora: En la entrevista apócrifa de Santiago Lavoe que se incluye al final de Por si nos da el tiempo — "Ella también escribía poscrítica" (67) - y a propósito de una primera pregunta del entrevistador sobre cierto "hilo autobiográfico que recorre los Desencuentros de la modernidad" (67), Julio X Ramos responde con el recuerdo impreciso de una afirmación que Ricardo Piglia le atribuye a su emblemático personaje Emilio Renzi - "uno de los grandes críticos literarios latinoamericanos" (70), según Ramos—: "La crítica es una forma de la autobiografía" (67; énfasis del autor). Sin embargo, Ramos parece concebir de otra manera el vínculo entre la crítica y la vida: "En 1989, cuando salió la edición mexicana, murió mi tío Pepón Arroyo. Traté de dedicarle los Desencuentros [...] por la historia que me donó frente al mar de Isla Verde en junio del 83" (73). En este orden de ideas, no deja de resultar significativo que lo que termina ocupando el lugar de la "entrevista" supuestamente concebida para ser publicada con Desencuentros en la reedición chilena de este texto (2003) sea el breve ensayo "Migratorias", publicado primero en Paradojas de la letra (1996).

Julio: La frase de Piglia se ha citado mucho. Pero no siempre al citarla - por ejemplo, en Por si nos da el tiempo - uno se percata de la complejidad de sus paradojas, y se corre el riesgo de leer allí una equivalencia inmediata entre vida y lectura. En Por si nos da el tiempo citaba mal a Piglia, quien había escrito en Formas breves algo distinto: "La crítica es la forma moderna de la autobiografía. Uno escribe su vida cuando cree escribir sus lecturas" (141). Piglia tenía una capacidad extraordinaria de condensación. Hay incluso una deriva de la condensación a la forma de la consigna, la frase guerrera, que Piglia traslada al escritorio polémico de la literatura. Para empezar, la cita complica la relación de prioridad mimética entre experiencia y lectura, en la medida en que la lectura, especialmente para el crítico, se trenza en la experiencia y puede llegar a modelarla. Después de todo, pareciera que vivimos de - y para- leer e interpretar. Pero no estoy tan seguro de que "la crítica" sea necesariamente una forma de la autobiografía, al menos si pensamos que la autobiografía es un género moderno de la individuación. Sin duda, la crítica implica (y complica) al sujeto en el entramado de sus lecturas - de sus lecturas como experiencia vital—, pero hay aspectos de la vida de un sujeto (incluso de un lector) que desbordan el marco de la lectura y la forma individualizada de la autobiografía. Incluso, diría que hay aspectos del acto de la investigación que suponen un archivo, una dimensión compleja, colectiva, de la mediación y de la autoridad cultural.

No dudo que el giro de Piglia, cuando propone la lectura como un acto vital de primera mano, fuera un guiño o comentario ligeramente irónico a los lectores de Barthes, quien defendía el goce de la lectura como una práctica primaria, creativa. Uno podría pensar que esta cita también despliega un concepto moderno, borgeano, de la lectura, si no fuera porque el mismo Borges complica este tipo de clasificaciones al entramar, en múltiples ocasiones, el fracaso de la lectura ante el impacto de otras fuerzas vitales, potencias ilegibles, a veces letales, como le ocurre, por ejemplo, a Dahlman en "El Sur" o, en otro sentido, al mismo Lönnrot, el súper lector de "La muerte y la brújula".

Efectivamente, como señalas, la entrevista apócrifa de Santiago Lavoe debía luego convertirse en un apéndice de la segunda edición de Desencuentros que publicó Marisol Vera en Cuarto Propio en 2003, con un prólogo de Nelly Richard. Pero a las editoras no les convenció la idea de incluir la entrevista en el libro. No les convencía la mezcla de registros en un libro de crítica, de circulación universitaria. Menos mal, digo ahora - no porque quiera defender una ley de pureza de género, claro que no, sino porque la entrevista, en un libro como Desencuentros de la modernidad, se habría leído como una fuente de información sobre el resto del libro, 
y obviamente no lo era-. Esto nos recuerda que los efectos de la ficción dependen también de condiciones pragmáticas de lectura. Es decir, hasta la mezcla responde a ciertos protocolos, ¿no te parece?

En cambio, la segunda edición de Desencuentros en Chile incluyó el ensayo "Migratorias", una lectura contrapunteada de un poema de Martí firmado en Nueva York, y un poema de Tato Laviera, una de las figuras claves del Nuyorican Poets Café del Lower East Side; dos límites posibles de una genealogía del latinoamericanismo. Presenté "Migratorias" primeramente en la Feria del Libro de Tijuana (1993), donde ya se discutía mucho la cuestión de la frontera y de la migración, uno de los entre-lugares de los emergentes estudios postcoloniales. No es casual que aluda ahora, muchos años después, al ensayo clave de Silviano Santiago sobre el entre-lugar de la escritura en América Latina. Ese ensayo de Silviano produjo tempranamente un cruce o intersección entre la pregunta postestructuralista de la traducción y un modo inédito de pensar la teoría de la dependencia y el colonialismo, el viaje y la frontera, cuestión que Silviano retoma años después en su libro $O$ cosmopolitismo do pobre. "Migratorias" proponía una lectura de Martí como uno de los primeros intelectuales latinos de Nueva York, lo que implicaba una lectura polémica del "clásico" latinoamericanista y de los principios territoriales e identitarios que el propio discurso martiniano había contribuido a demarcar durante su larga estadía en Nueva York entre 1880 y 1895.

Para dar una idea de las discusiones o debates que estimularon este trabajo, te cuento también que presenté otra versión de "Migratorias" en un coloquio que organizó Josefina Ludmer en Yale University sobre el fin de siglo. Allí, varixs retomamos la discusión sobre el latinoamericanismo a la luz de la crisis de las categorías territoriales y de la experiencia diaspórica. Ya para entonces, la reflexión sobre la modernidad se cruzaba con los retos que la experiencia migratoria oponía a las categorías identitarias o territoriales del latinoamericanismo. En ese sentido, incluir "Migratorias" como un nuevo capítulo de Desencuentros en la edición chilena era un modo oblicuo de remitir el entramado histórico de un libro sobre el siglo XIX al presente de su escritura; un modo de sugerir algunas de las preguntas contemporáneas que habían estimulado la investigación histórica del pasado.

Eleonora: En "Migratorias", incluido en Paradojas de la Letra, hablas de la relación entre el intelectual y la escritura en medio de los procesos migratorios que lo fracturan. ¿Qué relación estableces con la escritura y cómo se refleja en ella tu propia experiencia migratoria?

Julio: Los poemas de Martí y de Tato Laviera que leía allí — "Domingo triste” y "Migración” — son elaboraciones muy distintas del lugar del fragmento o del resto en la poesía. Me interesaba contrapuntear sus voces. Permíteme recordar algunos versos. En el poema martiano, probablemente escrito entre 1886 y 1888, la fragmentación es una consecuencia del exilio o destierro: "Cáscara soy de mí, que en tierra ajena / gira, a la voluntad del viento huraño, / vacía, sin fruta, desgarrada, rota”. Ese desgarre del sujeto desencadena una dispersión radical de los elementos subjetivos en el poema, en ese punto donde "ya en mí no queda más que un reflejo mío, como guarda / la sal del mar la concha de la orilla”. El sujeto es eco o resonancia de la concha, un grano o una partícula separada de una totalidad. En Martí el exilio, inseparable de su experiencia en Nueva York, es un tropo de la modernidad, del poeta en la modernidad. La fractura o fragmentación produce melancolía, una ausencia radical, insuperable, pero, acaso por eso mismo, resulta constitutiva de la sutura poética. El poema de Laviera, "Migración", también aborda una distancia o separación, una fractura, ligada ahora a la temporalidad del olvido en el presente diaspórico del poema, en ese momento o lapso en el que el intérprete olvida las notas de una canción, "En mi Viejo San Juan”, una especie de himno popular de la migración puertorriqueña escrito en Nueva York por el compositor puertorriqueño Noel Estrada. En el poema de Tato se "cita" la letra de la canción, como si mediante el gesto y el acto de citar el himno abolerado, un clásico plebeyo, la poesía fuera capaz de potenciar performativamente una comunidad dispersa, a contrapelo de la dislocación entre el paisaje tropical de la canción citada y el invierno neoyorkino. No es casual que luego Juan Flores, al releer a Laviera, encontrara en ese performance de la canción una imagen para contrarrestar la fractura como un tropo que predomina en el importante libro de Arcadio Díaz Quiñones, La memoria rota. 
Si en Martí predominaba la metáfora de las raíces "arrancadas" de la "tierra mía” y su efecto melancólico, en el poema de Laviera se abría la ruta alternativa de las raíces portátiles que mencionaba en aquel ensayo.

Estos poemas escenificaban dos posiciones muy distintas ante la fragmentación y la experiencia migratoria. Pero también, como te decía antes, el ensayo "Migratorias" era un intento de contraponer dos momentos diferenciados del latinoamericanismo. Primero, un posible momento inaugural - aunque ya paradójico en Martí, cuando escribe Nuestra América en Nueva York- y, luego, el del presente diaspórico desde donde era posible o necesario proponer una reinterpretación histórica o una genealogía del latinoamericanismo. Algunos reseñistas de Desencuentros de la modernidad identificaron esta interpretación diacrítica del latinoamericanismo como un efecto autobiográfico, aunque me parece que este tipo de explicaciones reduce la relación que hay entre experiencia, investigación y escritura a un correlato personal. Entre otras cosas, esta explicación, aunque motivada, aplana la tensión interna en la historia puertorriqueña entre distintas voces de la experiencia migratoria y la relación de lxs investigadores, alumnxs y docentes boricuas con el mundo universitario norteamericano donde me formé.

Eleonora: Por otra parte, a propósito de la teoría, ¿qué lugar le otorgas a la reformulación de algunos problemas neurálgicos del latinoamericanismo, como la que vemos emerger desde Desencuentros de la Modernidad en América Latina? ¿Podrías hacer una especie de puesta a punto de lo que serían tus "teóricos de cabecera"?

Julio: Te agradezco la pregunta, aunque sabes que siempre me ha preocupado tener lecturas de cabecera, especialmente teóricas. No lo digo por suspicacia antiteórica, obvio que no. La pregunta sobre la teoría incita a una discusión previa sobre la economía de la cita, la autoridad o el capital simbólico que la teoría acarrea en el intercambio y el mercado contemporáneo de las interpretaciones. Esa economía distribuye el lugar de los sujetos y de su autoridad en el campo de la crítica. Para mí un reto mayor radica en cómo impedir que la teoría se reifique o se convierta en un horizonte de referencia, fácilmente apropiable, mediante un gesto automático que finalmente paraliza la percepción crítica. Hoy me parece clave la pregunta sobre cómo desprogramar la sensibilidad crítica. No es casual, en ese sentido, que la teoría contemporánea, incluso en algunos de mis propios trabajos ensayísticos, como "Descarga acústica" (2010), intente pensar la relación entre la percepción y la producción conceptual que históricamente, al menos en Occidente, ha sido tan reacia a pensar el lugar del cuerpo que piensa.

Por otro lado, no tengo la menor duda de que uno también circula en las redes de una "inteligencia general" teórica. Al menos desde la década de 1970, el trabajo teórico ha abierto nuevos horizontes conceptuales o interpretativos en el campo de la crítica, detonantes de modos alternativos de escribir, leer, reinterpretar la historia y reensamblar archivos. El problema tiene que ver con el lugar de los modelos, las aplicaciones didácticas y el modo en que se organiza el poder universitario a partir de una nomenclatura, una especie de grilla de autoridad. Es algo que tú también te has planteado, por ejemplo, en tu lectura singular del psicoanálisis o del mismo Foucault en los años de tus trabajos y los de tus alumnxs y colegas sobre "los anormales" y las autorías excéntricas en los coloquios de Caracas y Mérida. Pero ahora hablamos no tan solo de la normalización de los cuerpos, sino de la normalización de los modos de interpretar. En el mundo actual de los bancos de datos y del capitalismo de las plataformas, la nomenclatura se suma al papel de ciertos vocabularios, key words que organizan los resúmenes requeridos por las revistas indexadas. La cita y estos vocabularios parecen ser las unidades mínimas de la producción de algoritmos.

Por eso, me parece que los múltiples proyectos de la decolonización del saber — desde el título clásico de Ngũgĩ wa Thiong'o, Decolonizingthe Mind - intentaron responder a una preocupación que sigue siendo insoslayable: la necesidad de impugnar las jerarquías entre la teoría metropolitana y otras formas del saber. Esas jerarquías históricas todavía pueden constatarse en dos ejes de una división global del trabajo y del poder universitario. Primero, en la distribución geopolítica de la autoridad intelectual entre las coordenadas del Norte y el Sur. En esa distribución desigual, el Sur históricamente producía particularidad, experiencia, actos de la imaginación o testimonios; en cambio, el Norte producía teorías o hipótesis generales. El segundo eje 
de esa jerarquía distribuye todavía hoy el orden de las formas y de los enunciados, determinando el peso de la "verdad" de los saberes de acuerdo con el valor universal de los géneros, marcos epistemológicos y modos de la escritura. Por ejemplo, el tratado es distinto del ensayo y de las formas híbridas de la crónica y del testimonio que operan en la zona de proximidad del acontecimiento empírico o de la experiencia.

Claro, los mapas heredados de la teoría de la dependencia (que dividían el mundo esquemáticamente entre centros y periferias) han cambiado radicalmente, al menos en cuanto a la producción teórica de las humanidades y a los estudios de la cultura se refiere. Aquella geopolítica del saber ha sido transformada por la globalización, los desplazamientos planetarios y también por las labores de intelectuales del Sur - pienso en E. W. Said, S. Hall, R. Guha, G. Spivak o A. Quijano-, cuyos trabajos reorientaron una zona importante de las discusiones en los centros metropolitanos. La distinción entre metrópoli y colonia-periferia se descentralizó en un nuevo deslinde postcolonial, entre otras cosas, por la presencia cada vez más notable de intelectuales de las antiguas colonias en los centros de producción del saber. Para el latinoamericanismo, este fenómeno había sido decisivo, incluso desde antes de la oleada de exiliados latinoamericanos que fueron a trabajar a las universidades de los Estados Unidos tras los golpes militares en Chile, Argentina, Uruguay, etc., en la década de 1970. Estos desplazamientos, ligados a las experiencias migratorias de las que hablamos antes, han complicado las fronteras entre Norte y Sur.

Creo que tu pregunta sobre los "problemas neurálgicos" del latinoamericanismo nos lleva a reflexionar brevemente sobre los principios de organización de su entramado conceptual, si es que hubiera uno solo. Permíteme ser un poco redundante: por latinoamericanismo entiendo los discursos sobre la integración interregional producidos desde América Latina o sobre América Latina. Estos discursos se multiplican y cobran urgencia particularmente en momentos de mundialización, globalización económica o tráfico transcultural y cosmopolita. Sus postulaciones de la integración y la diferencia ponen en juego distintas formas de mediación entre la particularidad y los conjuntos culturales o sociales más generales.

A su vez, la integración supone un despliegue o imposición de fuerzas, aunque siempre varía el tipo y el grado de la subordinación de las diferencias. En ese sentido, si bien el latinoamericanismo configura una especie de archivo de representaciones y conceptos de América Latina, también supone una serie de distinciones entre distintas prácticas intelectuales e instituciones que intervienen para "juntar" los fragmentos, las temporalidades distintas que se dispersan en la historia de la modernidad desigual. Estas prácticas y posicionamientos intelectuales son inseparables de la pugna por la legitimidad entre sujetos, saberes y disciplinas que intervienen en el recorte de fronteras, y que definen, mediante el recorte de límites, los intercambios "saludables" (o "peligrosos") entre el adentro y el afuera, entre las particularidades y las condiciones generales de integración (o desintegración) de un territorio. En ese sentido, el latinoamericanismo, al menos desde Martí y Bilbao, es un archivo de discursos sobre lo propio y lo ajeno, la América "nuestra" y la de "ellos", pero también es un modo de reflexionar sobre la forma de la autoridad capaz de producir la integración de ese nos-otros y de custodiar así el archivo.

Al considerar el latinoamericanismo como un archivo de representaciones y pugnas internas de autoridad, está claro que la discusión de Nuestra América en Desencuentros de la modernidad, así como los valiosos estudios posteriores de Alberto Moreiras y de Román de la Campa sobre el latinoamericanismo, reconocían la importancia que tuvo el análisis propuesto por Edward W. Said en Orientalism, un libro inaugural de la teoría postcolonial. Por otro lado, la genealogía de Said se refería específicamente a las representaciones europeas del "oriental" en los recortes de la diferencia que hacían posible la demarcación y autodefinición del sujeto europeo en distintas etapas de su expansión imperial. En cambio, en el latinoamericanismo de Martí, Rodó o Ángel Rama la pulsión integradora de intelectuales vernáculos (aunque siempre estaban relacionados con cierta movilidad transnacional) se distingue del latinoamericanismo-orientalista que era visto como una panoplia de saberes metropolitanos sobre la diferencia latinoamericana. A este se le ha relacionado con los llamados estudios de área en la geopolítica de la academia norteamericana. Esta distinción sigue pareciéndome necesaria: presiona a tomar en cuenta el correlato de los saberes subyugados o alternativos, una cuestión que 
luego sería clave, ya en los años 2000, para el giro decolonial que tomarían algunas de estas discusiones sobre las epistemologías del sur, en palabras de Boaventura de Sousa Santos.

Eleonora: Más allá de lo que hemos conversado hasta ahora, quiero insistir en esto: ¿qué dirías a propósito de tu relación con el archivo y tu trabajo documental? ¿Cómo esa pulsión investigativa se vincula con el trabajo de campo y con el acercamiento más vital y menos libresco al otro que evidentemente, y a juzgar por una parte importante de tu trabajo, moviliza tu interés?

Julio: Aquí me gustaría darle vueltas a una paradoja que tal vez me ayude a ubicar el trabajo de archivo y las presiones de lo "real" a las que responde. Es cierto, por un lado, que ahí hay, como dices, "un acercamiento más vital y menos libresco al otro", aunque, al plantearlo de tal modo y al oponer el acercamiento "vital" al "libresco", se podría matizar lo que hay de libresco en el propio vitalismo. Me temo que, en mi camino al documental, desde el primer trabajo sobre la peregrinación de San Lázaro-Babalú Ayé comenzado 1993 -el santo de los leprosos y de los enfermos-, la aproximación documental a la vida o a la experiencia estaba mediada por una serie de discusiones conceptuales, teóricas o literarias, es decir, bastante librescas. Esto, debo reconocerlo, es un problema para lxs documentalistas amigxs, quienes, con bastante razón, nunca me han considerado un documentalista, sino alguien que llega a las formas documentales desde otros campos o intereses. En algunos casos, la maraña de mediaciones textuales no le corresponde a uno, sino también a las personas a quienes uno entrevista. Por ejemplo, cuando Silvia Rivera Cusicanqui, la socióloga anarquista boliviana, ve las ballenas en los acantilados de Mendocino, asocia su color gris con el cheje, una categoría de su propio pensamiento teórico. Esto no le quita ninguna vitalidad ni singularidad a su discurso en Mar Arriba: los conjuros de Silvia Rivera Cusicanqui (2011). Otro ejemplo todavía más dramático de la mediación literaria del acto documental emerge en Retornar a La Habana con Guillén Landrián (que dirigí y produje con Raydel Araoz, como te había dicho antes) durante el intenso relato que cuenta Gretel Alfonso sobre la muerte de su marido, Guillén Landrián, cineasta experimental afrocubano, preso y psiquiatrizado por muchos años, exiliado con su pareja, Gretel, en Miami, hasta que lo acabó el cáncer en el 2003.

Por otro lado, esto implica un cambio significativo en la noción del archivo. El concepto del archivo ha pasado por una serie de mutaciones importantes en los últimos 50 años, transformaciones relevantes para tu pregunta, y para la tensión entre lo "real” y la "mediación" que me planteas. Estas transformaciones tienen que ver, primeramente, con el llamado posestructuralismo: el paso del archivismo historiográfico de F. Braudel a la Arqueología del saber de Foucault, donde el archivo pasa a ser el horizonte de protocolos y condiciones formales que hacen posible la producción de enunciados en un campo disciplinario específico. Ahí, Foucault desplaza la discusión del archivo, hasta entonces sinónimo generalmente del espacio de memorialización del poder, a la pregunta por las condiciones y lugares de enunciación del saber en un campo disciplinario dado. En Mal de archivo, Derrida produce un tercer momento de la discusión, vinculada ahora, por un lado, con la figura, poderosa siempre, del arconte, el custodio del archivo, y, por otro, del arché, la traza del origen fundante de las formas occidentales de memorialización de la ley. Siento afinidad con la intervención reciente de Andrés M. Tello en estas discusiones en Anarchivismo: tecnologias politicas del archivo, pero también con las resignificaciones de la discusión sobre el archivo en el campo audiovisual, donde el trabajo de archivo está ligado a las discusiones sobre el arte del metraje encontrado, la apropiación y la posproducción. Esto tiene que ver con la arqueología de los medios y con la forma del ensayo fílmico, tema pendiente que vuelve a surgir luego en una de tus preguntas posteriores sobre mi incursión audiovisual.

Desde mi investigación sobre el periodismo en La Nación de Buenos Aires, donde Martí publicó una buena parte de sus crónicas sobre los Estados Unidos en el transcurso de más de una década, ha habido distintos momentos de mi trayectoria (tan irregular) que han sido marcados por la investigación de archivo. La pulsión de archivo respondía inicialmente a la necesidad de documentar algunas hipótesis sobre el cambio de la literatura en la prensa del siglo XIX, lo que acercaba el trabajo de uno a ciertas preocupaciones de un nuevo archivismo interdisciplinario; es decir, no circunscrito ni a la filología ni a la historia, las dos disciplinas tradicionales que regían las ideologías del archivo. Más recientemente, después de mi retiro de Berkeley, he 
elaborado varios proyectos de investigación audiovisual que me llevaron de vuelta a la forma documental, un interés que se había iniciado con La Promesa, un documental etnográfico que produje y codirigí en 1995. Los proyectos recientes sobre Guillén Landrián (2014) y Diego Rivera en Detroit (2017) conllevaron un tipo de investigación sobre la papelería y la imaginería provenientes de distintos tipos de archivos, además de una reflexión sobre los archivos o texturas archivísticas con que trabajaba.

Eleonora: En 1992, publicaste una antología de textos sobre los escritos de la anarquista y feminista obrera Luisa Capetillo en el Puerto Rico de las primeras décadas del siglo XX: Amor y anarquía. Los escritos de Luisa Capetillo. Me gustaría que habláramos un poco de lo que significó ese proyecto en su momento, y lo que significa que estés por reeditarlo ahora. Sé que esta nueva edición involucra también una selección de textos sobre la autora: voces que dialogan con el agudo prólogo que introduce tu selección.

Julio: Efectivamente, tras las revueltas del 2019 en Puerto Rico y la vitalidad de las versiones recientes del anarquismo entre las nuevas generaciones de activistas puertorriqueñxs y caribeñxs, la figura y los escritos de Luisa Capetillo, anarquista y feminista histórica, ha recobrado relieve. Capetillo era una escritora anarquista, feminista y obrera. Tenía una relación distinta con la lengua, con la autoría y la noción misma del libro. Incluirla en la misma colección de clásicos donde figuraban Luis Lloréns Torres, Antonio S. Pedreira o Luis Palés Matos, por ejemplo, era un reto a la autoridad de la institución literaria, un modo de interrogar sus recortes históricos, los regímenes de inclusión y de exclusión que gobernaban su archivo. La propuesta de una selección de los escritos de Capetillo — que no habían vuelto a publicarse desde sus primeras ediciones a principios del siglo XX - tuvo muy buena acogida en la editorial, lo que demostraba que la "institución” y su economía del valor literario se adentraba ya en un proceso de cambio bastante radical.

La selección que hice para Ediciones Huracán facilitó la lectura de sus textos, aunque, claro, era una selección, un recorte. Se publicó con un prólogo extenso, que luego incluí en Paradojas de la letra (1996) y en otras ediciones posteriores de mis ensayos. El prólogo estaba recorrido por dos discusiones teóricas. Primero, la discusión en torno a la literatura menor, concepto que Deleuze elaboró en su lectura de Kafka. Deleuze escribía sobre un clásico de la literatura mundial, aunque la cuestión de la minoridad para Deleuze tiene menos que ver con esa dimensión institucional del canon, que con las operaciones diferenciales de Kafka - judío de zona fronteriza - en el interior de la lengua alemana, la lengua "mayor” de Goethe. Segundo, me resultó clave la discusión sobre las tretas del débil que Josefina Ludmer inició con su formidable lectura de la "Carta a Sor Filotea” de Sor Juana Inés de la Cruz. En su lectura de la carta de Sor Juana a su superior, el obispo de Puebla, Ludmer proponía un acercamiento al juego posicional de la subalternidad o marginalidad de los sujetos marcados por la diferencia y la exclusión. Esto generaba un cortocircuito en la interpelación identitaria, pues el sujeto llamado "menor" designa una pragmática, una serie de estrategias de posicionamiento. Así, Ludmer evitaba el peligro de la alteridad esencializada o de la diferencia absoluta. A estas estrategias, Ludmer les llamó las tretas del débil. Ante la instancia de Capetillo, estas discusiones alentaban una pregunta sobre los modos de autorización de Capetillo y sus paradojas. Estas paradojas de la autorización evidentemente retaban el tipo de juicio o evaluación que definía la crítica universitaria, aunque intervenía, sin duda, en un debate sobre el papel de los letrados en la cultura. Ya estaba bastante claro para 1992 que el marco de la ciudad letrada de Rama operaba con un concepto reducido de la letra y de la literatura, un debate que ya había iniciado en Desencuentros de la modernidad. Ni la letra ni la literatura eran dominio exclusivo de los letrados. Por ejemplo, me interesaba mucho el trabajo de Capetillo como lectora en fábricas de cigarros en Puerto Rico y otros centros de trabajo en Nueva York, La Habana, Tampa o Cayo Hueso. La lectura en las fábricas reinscribía una lógica de la mediación entre la letra y el mundo bastante ilustrado - aunque mayormente ágrafo- de lxs artesanxs. La mediación misma ubicaba a la escritora obrera (y a la lectora en las fábricas) en un entrelugar complejo, en las tensiones de una división del trabajo sobre las técnicas de representación. Al enfatizar este tipo de contradicciones internas al acto de la escritura, intentaba también evitar cualquier idealización de la escritura-otra o subalterna de Capetillo. Creo que este era un modo de responder a una pregunta que surge con frecuencia cuando uno trabaja materiales marginales o minoritarios: la suspicacia ante el riesgo 
de reificación de la diferencia en un discurso identitario o estereotipado. Tal como argumenté luego, en los ensayos sobre Flora Tristán (2011) o sobre el cine de Guillén Landrián (2019), el acercamiento a las formas minoritarias explicita más bien la economía de valores normativos — la lógica de las exclusiones, la ley de las instituciones culturales-.

Eleonora: Y la literatura, ¿qué piensas de la literatura, más allá de que tu trabajo crítico te ha llevado a explorar otros materiales y otros lenguajes (la música, la fotografía, el cine, el arte), como un medio para pensar la cultura latinoamericana y sus bordes problemáticos?

Julio: Bueno, de entrada, déjame decirte que leo más literatura ahora que antes, aunque no sé si lea "mejor". ¡Jé! Leo de otro modo, a veces más lento, a otro ritmo. Para mí esta desaceleración ha sido inevitable, pero también necesaria, como un modo de potenciar cierto tipo de reflexión a contrapelo del productivismo académico. A decir verdad, nunca acepté el llamado de guerra del amigo John Beverley "against literature", "contra la literaura". Cuando John publicó aquel libro, el profe se instalaba en un doble frente de polémicas: por un lado, el debate entre el testimonio y la literatura del boom, y, por otro, el debate de los Estudios Culturales durante los mismos años en los que Beverley y Spivak colaboraron en la fundación de ese programa en la Universidad de Pittsburgh. Cuando se posicionaba "en contra de la literatura", Beverley polemizaba contra una o varias ideologías literarias identificadas con la defensa de la autonomía y del privilegio estético, eso que él mismo llamó luego el neoarielismo. A mí mismo me ha llamado neoarielista, aunque espero que haya sido un poco en broma, acaso como un modo de comentar irónicamente mi deriva hacia el ensayismo. Demás está decirte que no estoy de acuerdo, aunque hay algo, por cierto, en la deriva hacia el ensayo que se confunde fácilmente con la tradición esteticista del ensayo, lo que llevaría a una discusión más amplia sobre las distintas formas del ensayismo contemporáneo. Recuerdo bien un seminario sobre estudios culturales que me tocó compartir con Beverley en el Centro Ludwig, un curso patrocinado por el Social Science Research Council. Como corpus de trabajo, llevé una serie de materiales híbridos, que comenzaban con los Diarios de campaña de Martí y cerraban con P. M., el cortometraje de Orlando Jiménez y Sabá Cabrera Infante censurado por Fidel Castro en 1961 (la censura como una escena primaria de la política cultural). Después de que comenté la paradoja de los Diarios de campaña, considerado por Lezama como una de las obras fundamentales de la literatura cubana, de buenas a primeras, John nos invitó a analizar la frase "Fuck Martí", un gesto iconoclasta que, claro, no pasó inadvertido entre los asistentes del seminario, que incluía a varias figuras de la oficialidad cultural cubana. Creo que la crítica de John a la literatura representaba una posición iconoclasta que, de hecho, generó debates muy necesarios en ciertos contextos. Pero, al radicalizar los antagonismos, su posición tendía a confundir la literatura con el privilegio o la prioridad de la mirada o la autoridad estética en las configuraciones históricas de las culturas nacionales y del latinoamericanismo mismo. A eso nos referimos por arielismo. Sería ocioso, a estas alturas, ponerse uno a demostrar que la práctica literaria no equivale al privilegio de un excepcionalismo estético en el análisis de la vida o de la política. En ese punto, mi respuesta a Beverley era de corte histórico. Me parecía necesario distinguir entre la intervención estético-política de distintas inflexiones y las divergencias de los estudios culturales latinoamericanos; por ejemplo, entre las prácticas interpretativas y las intervenciones críticas de Beatriz Sarlo y de Nelly Richard en la década del 2000. Incluso en los trabajos de Jesús Martín Barbero, en la deriva de los estudios culturales hacia los medios, operaba un concepto de la estética; reflexión que también ocuparía a Nestor García Canclini después del periodo más sociologizante de su trabajo cultural. Decir que todo recurso a la estética suponía una reemergencia del arielismo era un modo de cancelar las divergencias ineludibles de la teoría latinoamericana, no solo del latinoamericanismo.

Por otro lado, cada día me resulta más difícil trabajar con un concepto orgánico, centralizado, de la literatura. La literatura contemporánea opera en un campo expandido de formas y fuerzas, lo que a su vez encuentra un correlato en la deriva de muchxs investigadorxs que buscan repensar y practicar el trabajo transdisciplinario para plantear, por ejemplo, la relación entre la letra y otros regímenes de percepción. Es decir, la crítica de la autonomía del objeto literario, en trabajos, por ejemplo, como los de Florencia Garramuño sobre la inespecificidad de la literatura, posibilitan la proliferación actual de acercamientos a la 
cultura visual o sonora, sin la necesidad de los marcos habituales. En cierto sentido, la sinestesia —el cruce entre regímenes sensoriales- se convierte en un tropo o principio organizativo de la literatura expandida. Por otro lado, uno se pregunta si esa fluidez de las formas inespecíficas no corresponde a la misma lógica de la producción flexible y de la intercambiabilidad de las mercancías, cuyo principio semiótico sería el de la traducibilidad universal de las formas en una sola: el dinero. En ese sentido, el dinero siempre ha sido una forma posautonómica.

Eleonora: Uno de los problemas acerca de los cuales reflexionas en Desencuentros de la Modernidad en América Latina es el del intelectual que se abre camino en el marco de una autonomización de las letras, lo que supone también una relación problemática con el Estado. Quisiera saber cómo piensas la función del intelectual en tiempos de posautonomía. Y, en este orden de ideas, cuál es el lugar de la crítica como práctica intelectual: ¿hay algún lugar posible aún para la crítica cultural? ¿Cuáles serían, de haberlo, en tu opinión, las coordenadas de ese lugar? O, incluso, ¿cuáles serían las maneras de existir y de seguir produciendo e interviniendo críticamente en las políticas del sentido que hoy organizan lo social?

Julio: La autonomía había sido un principio de organización del campo literario e intelectual moderno. Como reclamo, se sostenía en la autorización del valor social de sus formas en función de una serie de mediaciones y operaciones técnicas que proyectaban su especificidad. La posautonomía supone entonces una crítica de la "propiedad" e inmanencia de la literatura como horizonte normativo y fuente de legitimidad. Uno tal vez puede cuestionar el tipo de temporalidad que supone el "pos" de la autonomía en la propuesta de Ludmer; o insistir un poco más en la coexistencia y simultaneidad entre ciertas tendencias autonomizantes y otras heterónomas en el momento contemporáneo. Pero de lo que no cabe duda es de que los debates contemporáneos sobre los marcos que hasta hace relativamente poco garantizaban la especificidad del objeto literario bajo un régimen de visibilidad o de reconocimiento no operan ya con la misma consistencia didáctica o clasificatoria. Me parece que el género híbrido de la crónica —en los ejemplos tan notables de Monsiváis, María Moreno o Pedro Lemebel—es una instancia emblemática de literatura posautonómica latinoamericana.

Por otro lado, está claro, al hablar de una condición posautonómica de la literatura contemporánea, que no nos referimos exclusivamente a rasgos formales o estilísticos, sino a la fractura de una ideología moderna que le asignaba a la literatura (a la estética en general) una función superior o excepcional en la organización, ya sea de los relatos sociales de subjetivación o, incluso, de los contrarrelatos modernos de la transgresión.

Tal vez, podríamos hablar de la condición posautonómica del trabajo cultural en términos más amplios, en la intersección entre nuevas formas laborales, creación de estilos de vida y redes de sociabilidad e intervención política. En ese sentido, son muy interesantes los trabajos de Reinaldo Laddaga, especialmente Estética de la emergencia, que desbordan los vocabularios habituales de la crítica cultural, sin perder de vista la pregunta por la crisis de los espacios históricos de la cultura y la emergencia de nuevas formas y emplazamientos. Quiero mencionar brevemente un aspecto de la vida material de estos cambios, ligados a la producción y circulación del objeto-libro en Puerto Rico. Consideremos, por ejemplo, el alcance que han recobrado las nuevas editoriales independientes en los últimos años. Me refiero a La Imprenta, dirigida por la poeta Nicole Delgado, y a la Editorial Educación Emergente fundada por Lissette Roldón Collazo y Beatriz Llenín Figueroa, por dar solo dos ejemplos. Estas editoriales son los espacios de un nuevo activismo estético-político que llega a su pico de intensificación durante la revuelta del 2019. Estas alternativas implican nuevos modos de organizar la vida material de la cultura y su relación con el trabajo, la tecnología y los vínculos afectivos de lo común. Cuando Naomi Klein escribió su libro sobre el capitalismo del desastre en Puerto Rico, a los pocos meses del paso del huracán María que devastó la isla en septiembre de 2018, notó la gestión cada vez mayor de los nuevos colectivos en la reorganización política de los discursos de oposición, pero no prestó atención al papel de lxs músicos, esritorxs, artistas visuales y documentalistas en la conjugación de lxs sujetxs y redes múltiples de disidencia que unos meses después de la visita de N. Klein a la isla salieron a la calle a exigir la renuncia de Ricardo Roselló en julio del 2019. 
Por otro lado, no hay ninguna razón para idealizar las condiciones posautonómicas en que emergen estas nuevas alternativas y formas de intervención cultural inseparables también de la precarización galopante del trabajo literario. Ha sido determinante la situación crítica, bastante extrema, en que se encuentra el mundo universitario, que hasta la última década había asegurado ciertas redes institucionales de discusión y lectura, de circulación de discursos y de inserción laboral de lxs escritorxs y críticxs. La crisis extrema de la universidad pública en Puerto Rico, agudizada en la última década, es solo un ejemplo reciente de la reconfiguración de los espacios universitarios que se ha dado en otros lugares de América Latina y ahora más que nunca en los EE. UU., donde también es dramática la tendencia a la precarización docente y las desigualdades internas entre los rangos, en el contexto general del cuestionamiento neoliberal de la universidad como institución, ahora sometida a la lógica del mercado y de la privatización. Está claro que esa experiencia se ha conocido bien en varios países latinoamericanos, por lo menos desde la década del 1980. El colapso universitario en Venezuela, inseparable de la guerra chavista contra la ciudad letrada, tiene otras dimensiones, pero desemboca en un colapso del mundo universitario sin precedentes. Estas son las condiciones de la llamada posautonomía. No hay que idealizarlas. En ciertas coyunturas está claro que es urgente renovar cierta defensa de la autonomía, al menos ante la presión e intervención del Estado (como en Venezuela), o ante las demandas cada vez mayores del mercado y la privatización. En ese sentido, la discusión sobre los límites de la autonomía se ubica todavía hoy en el corazón de la crítica cultural contemporánea como una aporía tal vez insuperable. No hay que ser un seguidor de T. W. Adorno para notar que la disolución de los límites de la autonomía y la especificidad desatan el peligro de la asimilación de las prácticas artísticas y de la crítica cultural misma al territorio indiferenciado, aplanado, de los medios y de las redes sociales.

Eleonora: Ya es relativamente extensa tu trayectoria como cineasta o realizador audiovisual: desde tu primer corto documental sobre la peregrinación de Lázaro-Babalú-Ayé en Cuba, La promesa (1995), hasta el más reciente ensayo visual Detroit'sRivera (2017), pasando por Mar arriba (2011) y Retornar a la Habana con Guillén Landrian (2014). Me gustaría que comentaras un poco acerca de esa suerte de deriva en tu trabajo intelectual, de la crítica más propiamente académica a la exploración de diversos registros audiovisuales. ¿A qué se debe ese desplazamiento? ¿Qué buscas en ese espacio de experimentación no solo visual, sino también intelectual?

Julio: Bueno, como sabes, no me considero un cineasta ni un realizador de cine. Hay gente que se dedica de lleno al cine. Desarrollan una relación con la técnica, con su medio de trabajo; algunxs han llegado por medio de una educación formal en las escuelas de cine, o, independientemente, con su laptop y un buen grupo o colectivo de colaboradores. Hay cineastas contemporáneos, como el cubano Miguel Coyula o el mexicano Nico Pereda, que tienen una formación profesional como cineastas, pero que abren líneas de fuga hacia formas alternativas de trabajo, modos de producción ajenos a temporalidad de la industria estatificada o del mercado. Solo los captura a veces cierta noción del "arte" (y de las curadurías o retrospectivas museológicas, que apoyan el régimen de reconocimiento). Es decir, me interesa mucho la pregunta (que se haría un crítico o un historiador) sobre cómo se forma un cineasta (un sujeto-cineasta) y en qué consiste su trabajo. O, simplemente, qué significa ser un cineasta hoy en día, cómo esta forma de "ser" queda atravesada por contradicciones y luchas. Las nuevas tecnologías han transformado y democratizado (relativamente) el medio. Con el audiovisual ha pasado algo paralelo a lo que Walter Benjamin señalaba sobre la escritura, luego de la extensión del periodismo y de las "cartas al editor": las nuevas tecnologías transforman y descentralizan el concepto del autor, o, en el caso del cine, del realizador-cineasta. Cada vez hay más aficionadxs que incursionamos en el medio sin necesidad de convertirnos en profesionales o en "cineastas", aunque está claro que la palabra acarrea su aura de excepcionalidad o de misterio creativo, hmm. ¿No te parece? Prefiero reservarla para la gente que se dedica full-time al cine, ya sea como realidad laboral o como fantasía.

Sin duda, hay modos diversos de interrumpir el aparato audiovisual y sus marcos discursivos. A veces, tengo la impresión de que el diálogo histórico entre la literatura y el cine tiene que ver con la reciprocidad de los 
intentos de interrupción y desprogramación mutua. Los documentales que mencionas están íntimamente ligados a otras zonas de mi trabajo de escritura e investigación.

Tal vez, el debate actual sobre el ensayo fílmico - lo que Antonio Weinrichter asocia con las operaciones conceptuales de la forma que piensa - puede ayudarnos a ubicar el intento de cruzar investigación y creación conceptual con el trabajo audiovisual contemporáneo. Sin duda, hay muchos y mejores ejemplos fílmicos de este género híbrido de no-ficción, una categoría reciente que cuenta ya, por cierto, con un canon, es decir, un régimen de reconocimiento. Pienso, por ejemplo, en los ensayos fílmicos de Chris Marker, de Harum Farocki o de Patricio Guzmán. Hay dos aspectos de ese debate que me interesan. Primero, obvio, su relación con la forma del ensayo como género literario, una forma reflexiva que históricamente produce un cortocircuito en los sistemas de auctoritas de su medio, ya sea para proponer una nueva relación del sujeto con la experiencia, o bien para desprogramar el horizonte institucional o normativo de un archivo. El primer aspecto vincula el ensayo fílmico con los modos de la autoficción. El segundo aspecto le da al ensayo fílmico una dimensión, digamos, arqueológica. La pulsión arqueológica se confirma no tan solo en el peso de la investigación de materiales del pasado, sino también en el registro (auto)reflexivo o crítico que el montaje de archivo desata en el recorrido de las texturas e imágenes del medio, provenientes del archivo o del contraarchivo. La tendencia arqueológica del ensayo visual muchas veces trabaja con metraje encontrado (foundfootage), como ocurre en las maravillosas películas de Peter Forgatz sobre el holocausto; otras veces conlleva una investigación de archivo histórico, como en el caso de Farocki con la historia del espacio fabril, o en algunos filmes de Marker, como El fondo del aire es rojo, ensamble de materiales sobre las revueltas alrededor de 1968.

Este segundo tipo de ensayo fílmico es un posible marco que permite ubicar mis documentales sobre Guillén Landrián y Diego Rivera en Detroit en un campo expandido de discusiones críticas. El primero de estos ejemplos, Retornar a La Habana con Guillén Landrián (2014), comenzó con una entrevista a Gretel Alfonso, viuda del documentalista experimental cubano. Gretel había regresado a La Habana en 2003, poco después de la muerte del director en Miami, donde la pareja había llegado con asilo político en 1989. Luego de la muerte de Guillen Landrián en el 2003, Gretel volvió a Cuba a enterrarlo en una tumba sin lápida y decidió quedarse. Rompió el pasaporte norteamericano y se quedó en La Habana. Por su parte, como dices, Detroit's Rivera: The Labor of Public Art (2017) es también un ensayo visual, lo que posiblemente se desprende de su trabajo de archivo. En este caso, se trataba de materiales fílmicos provenientes de múltiples archivos históricos, especialmente uno oficial, la Colección Ford de los Archivos Nacionales de los EE. UU., que incluye los materiales de cine industrial producidos por la División de Cine de la empresa Ford, el estudio creado por el magnate Henry Ford en 1914 que operó hasta 1954. Los materiales muestran una íntima relación entre el fordismo y el cine.

Cuando Diego Rivera fue contratado para pintar los murales monumentales sobre la industria de Detroit en 1932, Henry Ford personalmente le ordenó a uno de los camarógrafos de la División de Cine de la empresa que lo filmara con regularidad. Estos materiales, que nunca habían sido editados hasta ahora, se encuentran depositados en la Colección Ford de los Archivos Nacionales de EE. UU. Cuando empecé este proyecto cerca del 2010 (poco después de retirarme de Berkeley), había escrito ya un par de ensayos sobre Diego Rivera. Me interesaba mucho el tema del trabajo, tanto por el peso de las ideologías productivistas legadas de la modernidad como por su colapso, en las nuevas reflexiones y poéticas del "tiempo muerto", y por el desempleo (que en la ciudad de Detroit es rampante). Los murales de Rivera sobre la línea de ensamblaje en la River Rouge - para entonces, el complejo fabril más grande del mundo, que empleaba cerca de 125.000 obreroseran el objeto idóneo para abordar la relación entre arte y fordismo. La filmación del proceso de producción del mural por la División de Cine de la empresa añadía un componente fílmico extraordinario a los materiales. Hay una relación profunda entre el fordismo y el cine que no se ha analizado lo suficiente. No me refiero simplemente a la afición que Henry Ford mostraba por el cine y su proyecto de convertir a Detroit en una de las capitales globales de la producción fílmica. Me refiero a una relación entre cine y productivismo que conjuga, por un lado, una nueva ontología del objeto producido en serie, y, por otro, la temporalidad de la 
línea de ensamblaje y su relación histórica con los avances de las teorías y la práctica del montaje. De ahí la importancia del productivismo de Dziga Vértov en El hombre de la cámara durante todo el proceso de investigación y las cuatro o cinco etapas de la edición, primero con Martín Yernazian (tres cortes iniciales) y finalmente con Tatiana Rojas, quien terminó el trabajo ahí por el 2016. Pero si la visión de la máquina en Vértov era de un optimismo extremo, en cambio, Detroit's Rivera se organiza a partir del análisis crítico de los componentes fundamentales del fordismo y de su instrumentalización de la tecnología cinemática en la producción de un esquema audio-visual industrial.

El proceso de la investigación incorporó otros materiales de prensa y de cine obrero de la misma época para facilitar un contrapunto interno entre la producción de los frescos y otras representaciones del contexto, especialmente las luchas obreras durante los meses que Rivera y Frida Kahlo pasaron en Detroit entre 1932 y 1933. Sin recurrir a una voz en off, el medio-metraje explora los ritmos de trabajo físico (artesanal) que implica el arte en contraste con el lugar del cuerpo en la estricta línea de producción. Rivera reconoce allí una nueva política del cuerpo, que por cierto suponía también una antropotecnia, es decir, la panoplia de dispositivos para la creación de un "hombre nuevo", un sujeto intervenido farmacológicamente que interrumpe o borra cualquier frontera clara entre cuerpo y máquina, naturaleza y artificio. Esto se nota particularmente en la secuencia del documental sobre la empresa farmacéutica Parke Davis de Detroit, también cercana a Henry Ford, así como en la escena de la inoculación del "hombre nuevo" que causó grandes debates y un intento de censura del mural mientras Rivera lo pintaba en Detroit.

Es innegable que los murales de Rivera exhiben una ambivalencia notable ante los efectos destructivos de la tecnología y su relación con el nihilismo peculiar de las ideologías productivistas, de las cuales el fordismo es una culminación tardía. En los murales, esto se nota en la representación del agotamiento de los trabajadores - la extracción de energía física- en esa especie de via crucis del trabajo fabril en los pequeños paneles monocromáticos que Rivera ubica significativamente en la parte inferior. Pero en los murales de Rivera el peligro de la subsunción absoluta de la vida se resuelve en una visión optimista del destino humano y en una temporalidad encarnada en la criatura antropotécnica - el hombre nuevo- del trabajo productivo. No me parece que este aspecto progresista de la estética de Rivera se reduzca a la cuestión de su contrato con Edsel Ford. Rivera fue contratado por la empresa para producir una obra monumental del fordismo. Ford quería una épica del productivismo y de su papel heroico en él. Los murales hasta cierto punto fueron parte de todo un complejo dispositivo publicitario de la empresa (que incluía no solo producciones fílmicas, sino radiales y de prensa escrita). Rivera era un pintor comunista, crítico del capitalismo, sin duda. Pero compartía con Ford una narrativa del progreso basado en la intervención tecnológica y el trabajo productivo (cada vez más automatizado). De ahí se desprenden por lo menos dos zonas de tensión en los murales: la temática de la explotación del cuerpo (y la tendencia insistente de Rivera a estetizar el cuerpo del trabajo), y la relación también problemática del arte como forma de trabajo artesanal y los modos automatizados del trabajo fabril, proletarizado. El montaje de Detroit'sRivera intenta mostrar varios aspectos de estas tensiones y contradicciones.

Eleonora: Quisiera que me hablaras un poco de esta investigación cruzada entre la locura y la toxicomanía. Son dos problemas que te preocupan de manera particular. ¿Por qué? ¿Cómo se cruzan la pregunta por las subjetividades excéntricas y la que interroga a esos otros protocolos de la experiencia que se abren en la cultura a partir de las drogas y de lo que suponen tanto respecto a las nuevas formas de percepción como a las maneras distintas de relacionarse consigo mismo y con los otros?

Julio: Este giro nos lleva de vuelta a un aspecto de tu pregunta inicial sobre Por si nos da el tiempo con que abrimos la entrevista. No estoy muy seguro de que haya explícitamente una investigación cruzada entre locura y toxicomanía, aunque ambas experiencias me han ocupado en distintos momentos, tal vez hasta hoy en día. La cuestión de la locura se elabora con mucho más detenimiento y sutileza teórica en varios de tus trabajos sobre los llamados "anormales", así como en la tesis doctoral sobre delirio y escritura de nuestra amiga Celiner Ascanio en la Universidad Andina de Quito. Contigo y con Celiner comparto la atracción que ejerce el 
tratamiento de la locura en varios libros de Diamela Eltit, especialmente en El infarto del alma y Elpadre mío. Pero ahora quisiera enfocarme en la cuestión de las drogas y explicar por qué me parece necesario estudiar los regímenes de alteración contemporáneos y su relación con la literatura. Algunos de los materiales necesarios para la discusión teórica de estos temas se encuentran reunidos en la antología que edité e introduje con Lizardo Herrera, Droga, cultura y farmacolonialidad: la alteración narcográfica (2018). Los materiales de esta antología ejemplifican el potencial crítico de la discusión sobre las drogas y la alteración sensorial para varias disciplinas contemporáneas que entrecruzan la analítica de la droga con el abordaje de la formación de la subjetividad en regímenes biopolíticos.

No es nada casual, como sugieres, que la experiencia a veces extrema de la droga — su impacto en la voluntad y la autonomía, dos conceptos fundamentales en la teoría moderna del sujeto- suscite "protocolos de experiencia”. Así le llamaba Walter Benjamin a una zona de sus experimentos con el hachís, o más bien a la escritura de esos experimentos, reunida póstumamente en forma de libro. Curiosamente, la frase remite a un protocolo de investigación o de experimento, un género del laboratorio. Es decir, antes de que el concepto emigrara a Benjamin o luego al mismo Deleuze, para quien el protocolo resume la trayectoria rigurosa que exige una fuga o deserción, la frase, "protocolo de la experiencia", designaba la etapa de acopio y redacción de datos provenientes de un experimento científico. No creo que le hayamos dedicado suficiente atención a las paradojas del imaginario y del vocabulario de la experimentación en su traslado a las artes. Este vocabulario de procedencia experimental sigue vigente todavía hasta hoy en el tropo neovanguardista del laboratorio, espacio por excelencia de la extracción y (re)conversión de la experiencia en protocolos. La historia de la representación de la alteración química del sujeto en la literatura, a partir de las Confesiones de Thomas de Quincey, repite una escena primaria, donde el sujeto experimental cuenta (o confiesa, en el caso de Quincey) los efectos de su alteración, su desvío de un estado natural o normativo de la experiencia, para el beneficio futuro de la ciencia. Hay ciertamente protocolos más excéntricos, como los de Benjamin, cuyo registro - escrito durante el viaje o el arrebato - provenía de las notas de un médico amigo, quien frecuentemente acompañaba a los "investigadores" (incluido también Ernst Bloch) durante la travesía. Es muy difícil escribir, si no imposible, bajo los efectos de algunas drogas. Otras, como la anfetamina, diseñada en los laboratorios nazis como antropotecnia militar, ha sido un eficaz suplemento del productivismo y de la aceleración literaria — un suplemento energético-, pero no creo que los alucinógenos lo sean, a pesar de la insistencia de escritores como Phlip K. Dick. Para Benjamin, el experimento con el hachís y con la mezcalina se relacionaba con otro tipo de trabajo. Sus protocolos documentan el proceso de alteración que conduce a una iluminación profana, es decir, una operación surrealista convertida en protocolo paracientífico. En cambio, Junkie de William Burroughs recupera la tendencia didáctica del género, el tono descriptivo de la experiencia infernal del síndrome de la abstinencia, así como el potencial de la cura, primero, en The Farm, un centro de desintoxicación, luego, finalmente, mediante el reemplazo de la heroína por el yagé, la planta que estimula el viaje a América del Sur en Naked Lunch y en las famosas Cartas del yage entre Ginsberg y Burroughs. Antonio Escohotado, el investigador y heredero de los movimientos contraculturales, autor de una voluminosa Historia general de las drogas, defendía el derecho y la responsabilidad de probar el mayor número posible de las drogas sobre las que escribe, reclamando así - para este campo de investigación en el que nos movemos - una autoridad experimental basada en el conocimiento de primera mano. Como dicen los Orishas, al que le guste, que lo pruebe.

Sin duda, tal como lo sugieres, esto tiene que ver con la historia de los estados alterados de la conciencia y lo que llamas en tu pregunta las "subjetividades excéntricas" con que frecuentemente relacionamos la literatura moderna, su régimen de vidas excepcionales y su persistente exploración del anverso o las fracturas de la lógica instrumental. Estos recorridos muchas veces se mueven a contrapelo de las escansiones normativas del cuerpo ideal instalado en la triada de razón, ley y trabajo (cuya inversión literaria o estética pasa por el relevo heterodoxo de locura, transgresión y ocio o vagancia). En ese sentido, desde el siglo XIX, no es nada casual que la experiencia y reflexión sobre las drogas se empalme insistentemente con la reflexión sobre 
la aestesis y la percepción, como lo vio Susan Buck-Morss (1993) en un trabajo clave sobre la morfina, la an/estética y la fantasmagoría de las mercancías. La relación entre aestesis, anestesia y alteración sensorial, aunque fundamentada en relaciones materiales, lleva a pensar la droga como un tropo autoreflexivo de la literatura moderna, una figura donde la literatura condensa algunos de sus principios o valores constitutivos. Los ejemplos se multiplican a partir de aquella zona nocturna y colonial del romanticismo que comienza con Coleridge y De Quincey, que pasa por Poe y por Baudelaire antes de llegar al poema "Opiario" de Álvaro de Campos (y Fernando Pessoa). Digo que se trata de una zona del romanticismo puntualizada por desplazamientos coloniales porque en la mayoría de estos textos la experiencia extrema de la droga se da en los tránsitos y mediaciones de una geografía imperial, donde la droga marca la trayectoria de un viaje entre metrópolis y colonia o un recorrido de la frontera misma.

La antología de textos sobre droga y modernismo en América Latina que estoy preparado con Álvaro Contreras - una iniciativa de Álvaro- titulada tentativamente Farmacopea modernista, reúne una serie de escritos (poemas, crónicas, relatos, ensayos) que van desde el poema dedicado al hachís escrito por José Martí en 1875, hasta la novela corta Sebastián Guenard del puertorriqueño José de Diego Padró de 1924. Este recorte transversal del archivo altera los hábitos de lectura y la periodización de la literatura modernista. Los materiales muestran una política profana del cuerpo que se fragua en los márgenes de la alteración narcográfica, instigando nuevas aproximaciones interdisciplinarias de muchos materiales ignorados o poco vistos del periodo. Uno podría pensar incluso que esa zona "decadente" o maldita de la literatura modernista anticipa ciertos giros y preocupaciones de los movimientos contraculturales de los años 60 y 70 , vigentes hasta las ficciones (y autoficciones) del colombiano Andrés Caidedo, el venezolano Alejandro Rebolledo y el mexicano Julián Herbert, para mencionarte solo tres ejemplos del legado contracultural. De hecho, todavía hoy uno puede reconocer las ideologías modernas de la alteración sensorial como una aventura o línea de fuga de sujetos excéntricos o experimentales, lo que, por otro lado, no amengua la dimensión letal que cobran las drogas en la narcoliteratura de cuño más reciente (que se inicia con los primeros testimonios de sicarios y luego con la novela de Fernando Vallejo). En efecto, ahí estamos ante las dos zonas más previsibles o cristalizadas de la investigación sobre la droga en la literatura contemporánea.

Por otro lado, está claro que la droga no es solo un tropo o una metáfora. No puede reducirse a un discurso o a una retórica. Es un objeto, digamos, de una ontología relacional compleja que produce relaciones materiales entre la química, el cuerpo, la sensibilidad, la percepción, la subjetividad y el poder sobre la vida afectiva o incluso neuronal de los sujetos. Tal como lo mencionas en tu pregunta, la alteración sensorial transforma la relación de unx con los otros y consigo mismx. A tu pregunta sobre la droga y las relaciones (inter)subjetivas yo añadiría otra pregunta sobre el modo en que estas transformaciones son intervenidas o moduladas por distintos regímenes de alteración. El alcance de las drogas (legales o ilegales) en todos los aspectos de la vida orgánica y afectiva de los sujetos las hace susceptibles a la instrumentalización y al mercadeo en la panoplia de técnicas del gobierno de la vida. Lo que en BraveNew World de Huxley figuraba como el fármaco ficcional, el soma, de una sociedad productivista autoritaria, distópica, se ha transformado en el horizonte bastante generalizado del rediseño o modificación de la vida como una forma de bio - y psico- poder. Hay dos novelas contemporáneas que trabajan estas modulaciones de la vida de un modo afín a los regímenes de alteración que estamos comentando: Malas hierbas de Pedro Cabiya y Ornamento de Juan Cárdenas. Ambas son ficcionalizaciones de la vida en los espacios hiperracionalizados del laboratorio industrial farmacéutico. Son ficciones farmacológicas, muy atentas a las mutaciones y al rediseño de la vida.

Está claro entonces que ya no estamos hablando de la alteración de la conciencia simplemente como una aventura de la percepción, sino de la modulación de la sensibilidad, de la química misma de la vida (y del cerebro), en regímenes o máquinas de alteración. Es decir, lo que en la literatura contracultural (y frecuentemente en la ciencia ficción) aparecía como un experimento sensorial, subjetivo, reemerge ahora como la dimensión planetaria del capital farmacológico contemporáneo, tanto en sus zonas legales como ilegales. En estos regímenes, la subjetivación no pasa necesariamente por el juego de las interpelaciones o 
espejeos de la individuación, ni tampoco exclusivamente por la disciplina o gobierno de sí: su trayectoria está marcada por el rediseño de la sensibilidad y de la vida. Creo que este es un aspecto poco analizado aún de lo que Deleuze denominaba como la sociedad de control, regida por el endeudamiento de los sujetos, pero inseparable hoy en día de las adicciones y los múltiples enganches de la conectividad tecnológica, digital, tal como lo ha visto B. Stiegler en su ampliación del concepto de farmacología como una prótesis tecnológica. Estas modulaciones corresponden al rediseño de la vida y a la administración de la muerte, o de la muerteen-vida, tanto en las economías de un primer-mundo farmacologizado como en las economías del abandono y la precarización extrema.

En la narrativa puertorriqueña reciente, por ejemplo, uno encuentra varias exploraciones alternativas que solo voy a mencionar de pasada. Me refiero a los cuentos recientes de Cezanne Cardona, Vanessa Vilches y Josué Montijo, o, anteriormente, de Francisco Font Acevedo, en cuyos relatos la droga (u otras instancias de adicción) se intersecta con otras dimensiones de la transformación de la vida y la subjetividad en el horizonte del colapso colonial y la temporalidad ("tiempo muerto" o "improductivo") del desempleo.

De modos divergentes, toda esta literatura toca el corazón de los regímenes de alteración contemporánea dominados por el rediseño de la vida y de la subjetividad misma. Los regímenes de alteración presionan hoy por la reconsideración de las nociones naturalizadas de la subjetivación, en ese punto neurálgico (y neuronal) donde la modulación trastoca la antigua distinción entre naturaleza y artificio con que históricamente se analizaba y se juzgaba el papel de las drogas (como artificio) y la alteración de los estados "normativos" de la sensibilidad y de la conciencia. Lo que en la literatura contracultural y en la cienciaficción aparecía frecuentemente como formas excepcionales de experimentación y expansión se ha convertido en un horizonte industrial normativo de sociedades basadas en la alteración química de la vida y el poder sobre la muerte.

Eleonora: Para finalizar, no puedo dejar de referir este diálogo al presente. Y no solo a esta crisis radical que vivimos a nivel global a partir de la pandemia que nos ha condenado al aislamiento y a la imposibilidad de seguir adelante con nuestras cotidianidades inmunes y comunes. ¿Cómo pensar el futuro de América Latina a partir de este presente devastador?

Julio: Si te parece, voy a comenzar por el final de tu comentario-pregunta. Si uno piensa que la crisis o el fin del latinoamericanismo tiene que ver con el agotamiento de ciertos relatos del futuro (como destino común, integrado) que elaboraban sus intelectuales e instituciones, entonces, resulta imposible responder a la pregunta sobre “ ¿cómo pensar el futuro de América Latina?” sin detenerse a reflexionar sobre las condiciones, los conjuros, los poderes que hacen posible al pensamiento del futuro. Por otro lado, no hay que confundir el agotamiento del latinoamericanismo y sus relatos del futuro con la realidad múltiple y compleja de América Latina. Por ejemplo, la pandemia del coronavirus lleva a repensar los emplazamientos y estrategias de las revueltas latinoamericanas tras el efecto que tienen ahora las políticas de la emergencia y del aislamiento en las "asambleas de los cuerpos" (según la frase de la filósofa chilena Alejandra Castillo) que hasta hace unos pocos meses ocupaban las calles. ¿Cuál será el emplazamiento de los cuerpos bajo las nuevas condiciones de lucha y de restricciones?

Tu pregunta sobre el futuro nos trae de repente al presente de la escritura, al lugar donde me encuentro. Escribo en Nueva York, durante los días pico de las muertes causadas por la pandemia (comienzos de abril 2020). Se han reducido los contagios, pero las muertes siguen en aumento, cerca de 700 muertes diarias. ¿Cómo escribir sobre esto que estamos viviendo? El presente estaba allí desde el comienzo de tu entrevista. Es el tiempo de los giros y flexiones de las respuestas a tus preguntas y comentarios que, en efecto, me llamaban o interpelaban desde mucho antes del acontecer de la pandemia. Por eso mismo - por el hecho de que las preguntas y preocupaciones estaban situadas allí, en su presente, la entrevista remite a varios tiempos e intervalos, puntualizados por los anacronismos o desfases del diálogo, la correspondencia y sus contextos. Esto probablemente no le resta energía a un entramado que sigue siendo persistente: la apuesta diacrítica del margen por donde empezaste la entrevista, los tiempos contemporáneos, vitales, del diálogo, la insistencia 
de la letra (una especie de e-mail robado a E. A. Poe) que transita y pincha esta maraña común de relevos, preocupaciones e interrogantes compartidos.

Pero ahora, de pronto, nos topamos con el presente de la escritura en el momento final de la entrevista. Es como si la pregunta — que casi precipita un final — nos lanzara a releer las preguntas y respuestas pasadas, aunque ahora bajo la luz intensa o el peso que sobre nosotros ejerce un presente catastrófico. El presente de la amenaza del coronavirus introduce, como los grandes flujos del capital, una dimensión temporal "común" en todo (pan) el planeta, aunque esté clarísimo que el presente de la emergencia se vive de modos profundamente desiguales en los lugares tan distintos donde estamos: tú en Caracas, yo en Nueva York. Bajo el peso de la ley de este presente tan oscuro, todas las variaciones y presentes anteriores corren el riesgo de perder relevancia, sentido o especificidad. El presente de la catástrofe parece el tiempo de una interrupción pura, absoluta, ante la cual cada instancia de las experiencias pasadas da la impresión de desvanecerse o colapsar con todo lo demás que había quedado suspendido en el aire. Esto genera un peligro para la experiencia: el presentismo que se desprende de la naturalidad que gradualmente le otorgamos al presente como el momento aislado de un estado de emergencia o excepción.

En el territorio bastante más modesto de esta entrevista, comenzada hace un tiempo (¡algunas de tus preguntas estaban fechadas en el 2018!), esta pregunta última sobre el presente de la pandemia nos tienta a mirar atrás para revisar las preguntas y respuestas anteriores, lo que, por supuesto, no sería posible ni necesario aquí. No cabe duda de que un acontecimiento como este puede llevarnos a reconsiderar el sentido de lo que uno hacía antes, bajo las condiciones de una normalidad anterior a la crisis o a la emergencia. La catástrofe obliga, como se dice por ahí, a repensar las prioridades. Surge entonces la pregunta: ¿de qué "normalidad" estábamos hablando? ¿Cuándo termina el estado de emergencia y volvemos a la normalidad? ¿Se puede volver a la normalidad después de todo esto? Es muy probable que una experiencia como la del coronavirus como anteriormente lo fue la epidemia del sida para tantísima gente- inscriba en la memoria individual y colectiva un corte (una herida) entre un antes y un después de una biopolítica y gobierno de la vida, con consecuencias mayores en los diseños y operaciones inmunológicos del poder contemporáneo y la desigualdad entre las fuerzas que producen, sostienen o aniquilan la vida. Los efectos de la intensificación de esta operación inmunológica del poder ya pueden verse en los nuevos controles en la frontera, donde las detenciones de migrantes y personas con pleno derecho al refugio, durante los años anteriores a la pandemia, nos obligan a pensar que la "interrupción”, el momento excepcional de la catástrofe, ya se vivía en toda esa frontera como norma o ley. Pero, sin duda, la pandemia va a encrudecer la violencia de la política autoritaria del control de las fronteras en nombre de la seguridad y el control del territorio y sus principios de normalidad.

Tu pregunta me sitúa en otro lugar. No logro imaginar lo que significará la pandemia para mi prima Carolyn. Hay cosas que nunca se llegan a saber. Carolyn acababa de pasar tres semanas en Washington Heights con nosotrxs (i.e. Ana María, la fiera Laililú y un servidor) desde que comenzó el periodo del aislamiento. Pero antier decidió regresar a su lugar en Nueva Jersey. Nos despedimos a la entrada del puente George Washington que marca la frontera entre este barrio y el pequeño pueblo al otro lado del río Hudson donde Carolyn ha vivido toda su vida, desde que nació, muy cerca de aquí, en el Hospital Presbiteriano, hace 56 años. Nunca había pasado tantos días fuera de su casa como esta vez. Carolyn es la hija de mi única tía paterna, Carolina, mi madrina, quien emigró a Nueva York desde Cayey, Puerto Rico, cuando apenas tenía 5 o 6 años, tras la muerte de mi abuela materna y una separación traumática de su hermano, mi padre. Mi hermano Pedro Miguel y yo somos los únicos parientes que le quedamos a Carolyn después de la muerte de la tía Carolina hace tres años.

La observé subir un poco caótica con varias bolsas de ropa colgadas de los hombros y de cada brazo las escaleras que dan al puente. Sentí tristeza, pero percibí también el vigor persistente con que la prima Carolyn emprendió la caminata de regreso a casa. "I wanna go back home to my normal life" ["Quiero volver a casa a mi vida normal"]. Ella iba decidida a retomar algunas de las rutinas de una vida muy reducida desde siempre por el cerco de un aislamiento mayor, ese que mide implacablemente la "distancia social" del estigma, la "anormalidad" o discapacidad cognitiva o intelectual de la prima Carolyn. Recuerdo cuando se decía en la 
familia que Carolyn era retardada, como si a nos(otros) — lxs miembros de la familia que la veíamos como anormal - nos correspondiera el tiempo pleno del desarrollo o un destino muy diferente al suyo. ¿Cuál puede ser eso que ahora, en tu pregunta, has llamado la "cotidianidad inmune y común" en la experiencia de Carolyn? ¿Qué nos dice su discapacidad sobre las condiciones del estado de emergencia y la comunidad?

La epidemia expone las desigualdades tremendas que atraviesan el régimen del trabajo y también sus teorizaciones. Mientras se expande en estos mismos días el capital de la inteligencia artificial y las plataformas, se calcula que el desempleo va a sobrepasar los niveles de la Gran Depresión de los años 30, un referente económico de la crisis (referente económico inseparable de la consideración renovada sobre el estado de beneficencia y sobre el derecho universal al cuidado médico). La epidemia redistribuye los lugares del cuerpo del trabajo, profundiza la fractura entre la conectividad del cuerpo en los espacios virtuales del trabajo cognitivo y las labores de lxs que tienen que poner el cuerpo, su presencia vulnerable, en el lugar del trabajo. Han cerrado las grandes fábricas de producción automotriz, pero la producción alimentaria no ha podido detenerse. Varias fábricas de producción de carne han sido focos escandalosos de contagio. Los trabajadores de la agroindustria no paran de salir a los campos para producir alimentos. La pandemia intensifica el racismo en las fronteras, donde todavía hay cerca de 40.000 migrantes presxs, al mismo tiempo que intensifica la necesidad de trabajadores en los campos agrícolas, o en las calles de las ciudades, donde los migrantes, muchxs de ellxs indocumentadxs, son el soporte físico de toda la economía alimentaria, formal e informal, de la ciudad, que por cierto incluye a los mensajeros, cocineros, domésticxs, vendedores ambulantes, verduleros. La cuestión de la cadena de la producción y distribución alimentaria, así como de los empleos peor pagados y protegidos en la economía del cuidado, nos recuerdan las limitaciones insalvables de la teoría del postrabajo, su tendencia paradójicamente cartesiana a invisibilizar el trabajo físico, al otorgarle una prioridad insostenible al trabajo inmaterial o cognitivo aislado bajo los regímenes desiguales del posfordismo. El cuerpo sigue allí, como base del fundamento productivo-reproductivo, expuesto al riesgo del contagio y al presente catastrófico de la enunciación. Carolyn no trabaja. Ha trabajado antes, sí, por varios años, en Burger King y luego en un Boston Chicken Market, pero se declaró en huelga hace años, me dice. Otras veces dice, con un poco de ironía, que está jubilada, "like my cousin Julio" ["como mi primo Julio"]. Sus guerras en el trabajo fueron tremendas, me consta. Pero lo que ahora me preocupa no es que lleve años sin trabajar. Ahora, me preocupa que salga a alumbrar las calles desoladas de Ft. Lee con la sonrisa repetitiva y dislocada de siempre, y que los vecinos intenten expulsarla del edificio.

\section{Notas}

* Entrevista.

Licencia Creative Commons CC BY 4.0

Cómo citar esta entrevista: Cróquer Pedrón, Eleonora. "Vida y Crítica. Un diálogo con Julio Ramos". Cuadernos de Literatura, vol. 25, 2021. https://doi.org/10.11144/Javeriana.cl25.vcdj 